\title{
Production of Hybrid Chimeric PVX Particles Using a Combination of TMV and PVX-Based Expression Vectors
}

\author{
Christina Dickmeis ${ }^{1}$, Mareike Michaela Antonia Honickel ${ }^{1}$, Rainer Fischer ${ }^{1,2}$ and \\ Ulrich Commandeur ${ }^{1 *}$
}

${ }^{1}$ Institute for Molecular Biotechnology, RWTH Aachen University, Aachen, Germany, ${ }^{2}$ Fraunhofer Institute for Molecular Biology and Applied Ecology, Aachen, Germany

We have generated hybrid chimeric potato virus $X(P V X)$ particles by coexpression of different PVX coat protein fusions utilizing tobacco mosaic virus (TMV) and PVX-based expression vectors. Coinfection was achieved with a modified PVX overcoat vector displaying a fluorescent protein and a TMV vector expressing another PVX fluorescent

OPEN ACCESS

Edited by: George Peter Lomonossoff, John Innes Centre, UK

Reviewed by: Martha Magaretha O'Kennedy, Council for Scientific and Industrial

Research, South Africa Kashmir Singh,

Panjab University, India

*Correspondence: Ulrich Commandeur commandeur@molbiotech. rwth-aachen.de

Specialty section: This article was submitted to Plant Biotechnology, a section of the journal Frontiers in Bioengineering and Biotechnology

Received: 17 September 2015 Accepted: 04 November 2015 Published: 20 November 2015

Citation:

Dickmeis C, Honickel MMA, Fischer $R$ and Commandeur U (2015) Production of Hybrid Chimeric PVX Particles Using a Combination of TMV and PVX-Based Expression Vectors.

Front. Bioeng. Biotechnol. 3:189. doi: 10.3389/fbioe.2015.00189 overcoat fusion protein. Coexpression of the PVX-CP fusions in the same cells was confirmed by epifluorescence microscopy. Labeling with specific antibodies and transmission electron microscopy revealed chimeric particles displaying green fluorescent protein and mCherry on the surface. These data were corroborated by bimolecular fluorescence complementation. We used split-mCherry fragments as PVX coat fusions and confirmed an interaction between the split-mCherry fragments in coinfected cells. The presence of assembled split-mCherry on the surface confirmed the hybrid character of the chimeric particles.

Keywords: potato virus $X$, tobacco mosaic virus, hybrid chimeric particles, viral vectors, coexpression, fluorescent proteins, nanoparticles

\section{INTRODUCTION}

Plant virus particles offer an excellent tool for pharmaceutical and nanotechnological applications. They can consist of multiple identical copies of one or two coat protein (CP) subunits and can be easily modified by genetic engineering or chemical conjugation (Meunier et al., 2004; Chatterji et al., 2005; Steinmetz, 2010; Rego et al., 2013; Lee et al., 2014). Plant virus capsids offer suitable building blocks for areas of research and application as diverse as electronic devices, composite materials, and vaccine production. There is a growing demand for inexpensive vaccines that can be distributed and stored without maintaining the cold chain, particularly in developing countries which lack an appropriate infrastructure (Ma et al., 2005b). This exacerbates even simple infectious diseases and ultimately leads to a high child mortality rate (Hefferon, 2013). Although plant virus particles

Abbreviations: BiFC, bimolecular fluorescence complementation; C-mC, C-terminal part of split-mCherry; CP, coat protein; FDMV, foot and mouth disease virus; GFP, green fluorescent protein; HCV, hepatitis virus C; ISEM, immunosorbent transmission electron microscopy; mRFP, monomeric red fluorescent protein; N-mC, N-terminal part of split-mCherry; NMD, nonsense-mediated decay.; ORF, open reading frame; PBS, phosphate-buffered saline; PVX, potato virus X; RdRp, RNA-dependent RNA polymerase; TEM, transmission electron microscopy; TGB, triple gene block; TMV, tobacco mosaic virus. 
might also need cold storage after purification, the lifetime and stability in plant material is better compared to other vaccine production systems.

Plants are considered a promising alternative production system for pharmaceuticals and have been studied extensively over the past decades (Fischer et al., 2012; Lico et al., 2012; Melnik and Stoger, 2013). Plant virus particles or CPs are ideal for the presentation of epitopes (Porta and Lomonossoff, 1998; Yusibov et al., 2006; Morgenfeld et al., 2009; Rosenthal et al., 2014). They can be produced in large amounts in plants as bioreactors, with inexpensive growth conditions and a minimal risk of contamination with animal pathogens (Twyman et al., 2003; Ma et al., 2005a). Plant virus particles and CPs as carrier molecules enhance the immunogenicity of peptides by presenting them robustly to the immune system (Lomonossoff and Evans, 2014). When the target epitope is inserted at an appropriate site on the selected plant viral $\mathrm{CP}$, they can assemble to intact particles displaying the foreign peptide on the outer surface (Johnson et al., 1997). Immune responses against single pathogen epitopes are in most cases not sufficient to provide protection against an infection. Often different genotypes or subtypes of pathogens are found, e.g., the mammalian virus Hepatitis $C$ virus (HCV) (Simmonds et al., 2005). This makes a vaccine development difficult, which is further complicated by the degree of heterogeneity in infected individuals due to the pathogen mutation rate (Hayashi et al., 1999). The presentation of several different epitopes from the same pathogen or from several different pathogens is ideal for the construction of efficient vaccines (Sette et al., 2001; Awram et al., 2002).

Several plant viruses have been developed as epitope presentation systems. The most widely used are cowpea mosaic virus (CPMV) (Brennan et al., 2001; Gonzalez et al., 2009; Sainsbury et al., 2010) and tobacco mosaic virus (TMV) (Sugiyama et al., 1995; Porta and Lomonossoff, 1998). Another promising plant virus for epitope presentation is potato virus $X$ (PVX), the type member of the genus Potexvirus in the virus family Flexiviridae (Adams et al., 2004). Solanaceae (e.g., potato, tomato, and tobacco) are infected by PVX and the virus is transmitted mechanically from plant to plant (Koenig, 1971). PVX has a +ssRNA genome $6.4 \mathrm{~kb}$ in length, with a 5'-methylguanosine cap, a polyadenylated 3 ' tail, and five ORFs (Koonin, 1991; Kim and Hemenway, 1997). The RNA-dependent RNA polymerase ( $R d R p)$ is the first ORF and is the only virus protein needed for viral RNA synthesis and replication (Draghici et al., 2009). The next three ORFs overlap, and encode the p25, p12, and p8 triple gene block (TGB) proteins necessary for the cell-to-cell transport (Beck et al., 1991; Angell and Baulcombe, 1997; Verchot et al., 1998). The last ORF at the 3 ' end encodes the CP. Approximately $1270 \mathrm{CP}$ subunits assemble with the plus-strand RNA into the viral particle (Tollin and Wilson, 1988). Furthermore, the CP is also important for cell-to-cell movement and long distance transport through the plant (Chapman et al., 1992; Baulcombe et al., 1995; Cruz et al., 1998). The virus particles have a size of $515 \mathrm{~nm} \times 13.5 \mathrm{~nm}$ and are flexuous rods (Tollin and Wilson, 1988; Atabekov et al., 2007). Flexuous particles have, in general, the advantage of no intrinsic size limitations or packaging constraints and potentially many copies of the target peptide can be presented on the surface (Uhde et al., 2005). The N-terminal portion of the PVX CP is exposed on the virion surface (Koenig and Torrance, 1986; Baratova et al., 1992), making N-terminal fusions to the CP the ideal strategy for epitope presentation. Several epitopes had been presented as PVX CP fusions, including the 2F5 epitope of the human immunodeficiency virus (HIV) (Marusic et al., 2001), an epitope of the Influenza A virus nucleoprotein (Lico et al., 2009), and the R9 peptide of HCV (Uhde-Holzem et al., 2010). In all these cases, robust immune responses were achieved in animal models.

Limiting factors for peptide fusions to the PVX CP is the size and the isoelectric point (pI) of the target epitope. The inserted sequences can impair virus assembly and systemic infection (Uhde-Holzem et al., 2007). Thus far, the maximum epitope sequence that has been displayed as a direct CP fusion on the particle surface was 14 residues in length (Uhde-Holzem et al., 2010). For the display of larger sequences, the $2 \mathrm{~A}$ sequence from foot and mouth disease virus (FMDV) is inserted between the peptide and the $\mathrm{CP}$. The $2 \mathrm{~A}$ sequence confers a cotranslational ribosomal skip, leading to a production of non-fused CP and CP fusion product in a certain ratio depending on the amino acid sequence (Donnelly et al., 2001a,b). In this way, complete proteins can be displayed on the particle surface, creating the so-called overcoat (Cruz et al., 1996), which allows PVX particles to be used, for example, as optical probes for imaging in plant cells (Linnik et al., 2013). The stability and functionality of these particles were also confirmed in mammalian cells and tissues (Shukla et al., 2014).

In this study, we created a production system for hybrid chimeric PVX particles displaying different polypeptides as CP fusions. For this, we used combinations of PVX and TMV expression vectors, each expressing different PVX CP fusions. The coinfection capacity of PVX and TMV vectors has been described earlier and is, for example, used for the production of recombinant antibodies (Giritch et al., 2006), confirming the coexpression of different transgenes in the same cells. To prove the principle of the assembly of hybrid chimeric PVX virions, we chose the green fluorescent protein (GFP) and the red fluorescent protein mCherry, as well as a bimolecular fluorescence complementation (BiFC) system with split-mCherry as $\mathrm{CP}$ fusion proteins.

\section{MATERIALS AND METHODS}

\section{Plasmid Constructs}

The expression constructs containing the GFP and mCherry CP fusions were assembled using PCR to add PacI and NotI restriction sites. The PVX expression vectors pTCXI (GFP-2A-CP) and pTCXIIc (mCherry-2A-CP) were used as templates (Shukla et al., 2014). Forward primers PacI-GFP (5'-AGT TAA TTA ATG AGT AAA GGA GAA G-3') and PacI-mCherry (5'-AGT TAA TTA ATG GTG AGC AAG GGC G-3') with reverse primer CP-NotI (5'-TTG CGG CCG CTT ATG GTG GTG GTA G-3') were used. The resulting PCR products and the target TMV vector pJL36 [kindly provided by Lindbo (2007)] were digested with PacI and NotI (NEB). The final constructs were prepared by joining the fragments with T4-DNA ligase (Promega) overnight at $16^{\circ} \mathrm{C}$. The ligation products were introduced into Escherichia coli $\mathrm{DH} 5 \alpha$ and colonies were selected on LB plates supplemented with $50 \mathrm{mg} / \mathrm{ml}$ 
kanamycin overnight at $37^{\circ} \mathrm{C}$. Plasmid DNA was isolated from overnight cultures and sequenced. The resulting plasmids were called pTMV-GFP-2A-CP $\mathrm{P}_{\mathrm{PVx}}$ and pTMV-mCherry-2A-CP $\mathrm{PVX}_{\text {. }}$ The split-mCherry sequence was constructed essentially as described by Fan et al. (2008), with the mCherry split-site at residues 159/160. Either the C-terminal (NheI-C-mC: $5^{\prime}$-ACC AGC TAG CGC TAC CGG TCG CCA CCA TGG GCG CCC TGA AGG GCG AGA TC-3' and mCherry-BspEI: -5'-TCC GGA CTT GTA CAG CTC GTC CAT-3') or N-terminal (N-mCBspEI: $5^{\prime}$-CTT AAG AAG GTC AAA ATT TCT AGA TCC GGA GTC CTC GGG GTA CAT CCG CT-3' and TGB-fw: 5'-AAG GGC CAT TGC CGA TCT CAA GC-3') part of mCherry was amplified by PCR, adding the restriction sites NheI and BspEI for cloning in the PVX vector. After construction of the PVX vectors with the split-mCherry components (pPVX-N-mC-2A-CP and pPVX-C-mC-2A-CP), the sequence with the CP fusion construct was amplified by PCR adding the restriction sites PacI (PacI-N-mC: 5' -AGT TAA TTA ATG GTG AGC AAG GGC G-3' or PacI-C-mC: 5'-CGT GTT CTT GTC ATT AAT TAA TGG GCG CCC TGA AGG GCG AGA TC-3') and NotI (CP-NotI) for cloning into the TMV vector, resulting in expression vectors pTMV-N-mC-2A-CP ${ }_{\mathrm{PVX}}$ and pTMV-C-mC-2A-CP ${ }_{\mathrm{PVX}}$.

\section{Plant Inoculation and Maintenance}

For inoculation with PVX vectors, 4-week-old Nicotiana benthamiana plants were dusted with Celite 545 (3-4 leaves per plant) and then rubbed with $10 \mu \mathrm{g}$ plasmid DNA per leaf. PVX vectors were introduced into Agrobacterium tumefaciens strain GV3101:pMP90RK and TMV vectors were introduced into $A$. tumefaciens strain GV2260. The bacteria were cultivated at $26^{\circ} \mathrm{C}$ in YEB medium $(0.5 \%$ beef extract, $0.1 \%$ yeast extract, $0.5 \%$ peptone, $0.5 \%$ sucrose, and $2 \mathrm{mM} \mathrm{MgSO}_{4}$ ) supplemented with $100 \mathrm{mg} / \mathrm{l}$ carbenicillin, $50 \mathrm{mg} / \mathrm{l}$ rifampicin, and $25 \mathrm{mg} / \mathrm{l}$ kanamycin. The cultures were pre-induced with $10 \mathrm{mM}$ MES ( $\mathrm{pH} 5.6$ ), $10 \mathrm{mM}$ glucose, and $20 \mu \mathrm{M}$ acetosyringone after $24 \mathrm{~h}$ of growth. After $48 \mathrm{~h}$, the cultures were diluted to $\mathrm{OD}_{600 \mathrm{~nm}}=0.5$ for TMV vectors and $\mathrm{OD}_{600 \mathrm{~nm}}=1$ for $\mathrm{PVX}$ vectors with $2 \times$ infiltration medium [100 g/l sucrose, $3.6 \mathrm{~g} / \mathrm{l}$ glucose, $8.6 \mathrm{~g} / \mathrm{l}$ Murashige and Skoog (MS) salts, $\mathrm{pH}=5.6$ ] supplemented with $200 \mu \mathrm{M}$ acetosyringone and incubated for $30 \mathrm{~min}$ at room temperature. Four-week-old $N$. benthamiana plants were then inoculated by syringe without a needle and incubated at $26^{\circ} \mathrm{C}$ for $12 \mathrm{~h}$ in the dark at $20^{\circ} \mathrm{C}$ for $12 \mathrm{~h}$ in a phytochamber with constant light (25,000-30,000 lux).

\section{Protein Isolation and Analysis}

Total soluble protein was isolated from harvested leaves by homogenizing leaf tissue in two volumes of phosphate-buffered saline (PBS). Insoluble debris was removed by centrifugation $\left(13,000 \mathrm{rpm}, 10 \mathrm{~min}, 4^{\circ} \mathrm{C}\right)$ and protein samples were resolved by SDS-PAGE (Laemmli, 1970) after mixing plant sap with $5 \times$ reducing buffer (62.5 mM Tris- $\mathrm{HCl}$ pH 6.8, 30\% glycerol, 4\% SDS, 10\% 2 -mercaptoethanol, and $0.05 \%$ bromophenol blue). The samples were either visualized directly in the gel to confirm the presence of the fluorescent proteins or they were boiled for 5-10 min for western blotting. Samples were separated on $12 \%$ polyacrylamideSDS gels and then either stained with Coomassie Brilliant Blue or blotted onto a nitrocellulose membrane (HybondC, Amersham) for western blot analysis. The membranes were blocked for $1 \mathrm{~h}$ with 5\% skimmed milk in PBS and incubated with a polyclonal antibody against PVX CP (DSMZ, Braunschweig, Germany), TMV CP (Bioreba, Switzerland), DsRed, or GFP (GeneTex, Irvine, CA, USA) for at least $2 \mathrm{~h}$ at room temperature. The DsRed antibody recognizes mCherry because the latter is a monomeric form directly derived from DsRed. A monoclonal alkaline phosphatase-conjugated goat anti-rabbit antibody $\left(\mathrm{GAR}^{\mathrm{AP}}\right)$ was used as the secondary antibody (Dianova, Hamburg, Germany) and the signal was visualized with nitroblue tetrazolium chloride/5bromo-4-chloro-3-indolyphosphate p-toluidine salt (NBT/BCIP).

\section{Detection of Fluorescence}

The plants were monitored daily and analyzed for GFP fluorescence using a handheld UV lamp (7000 $\mu \mathrm{W}$, Novodirect, Kehl/ Rhein, Germany) and for mCherry fluorescence with green light (KL2500 LCD, Schott AG, Mainz, Germany) and a red filter. Pictures were taken with a Nikon Coolpix 5400 camera (Nikon, Düsseldorf, Germany). For microscopic analysis, plant parts were analyzed with a Biorevo BZ-9000 fluorescence microscope (Keyence, Neu-Isenburg, Germany).

\section{Particle Purification}

Plant material was harvested 14-21 dpi depending on the infection status, and $50 \mathrm{~g}$ of plant material was used for virus purification with a modified protocol from CIP (International Potato Center, Lima, Peru), as previously described (Uhde-Holzem et al., 2010). PEG precipitation was carried out as described in the original protocol, but the centrifugation on a sucrose cushion was skipped because we lost too many particles during this step. Therefore, the centrifugation of the pooled fractions of the sucrose gradient continued for at least $3 \mathrm{~h}$. The virus concentration was determined at $\mathrm{OD}_{260 \mathrm{~nm}}$ and the extinction coefficient of 3.0 for TMV because the TMV concentration in the mixtures tended to be greater.

\section{Transmission Electron Microscopy}

The particles were either directly adsorped to grids for transmission electron microscopy (TEM), or processed for immunosorbent transmission electron microscopy (ISEM) as followed. For the adsorption grids, $20 \mu \mathrm{g}$ of purified particles was incubated on Pioloform-coated 400-mesh nickel grids for $20 \mathrm{~min}$. For ISEM, the grids were coated with the first antibody either $\alpha$-PVX, $\alpha$-DsRed or $\alpha$-GFP antibodies diluted 1:10 in PBS for $20 \mathrm{~min}$. Unbound antibodies were washed off with PBST [PBS supplemented with $0.2 \%(\mathrm{w} / \mathrm{v})$ Tween 20 ] and the grids were blocked with $0.5 \%(\mathrm{v} / \mathrm{v})$ bovine serum albumin (BSA) in PBS for 15 min. Subsequently, the grids were incubated with $20 \mu \mathrm{g}$ of the particle preparation for 20 min, followed by washing with PBS. Captured PVX particles were analyzed for fluorescent proteins on the surface by immunogold staining. Therefore, the preparations were incubated for $2 \mathrm{~h}$ with the $\alpha$-PVX, $\alpha$-mCherry, or $\alpha$-GFP antibodies diluted 1:100 in PBS. Primary antibodies were detected by overnight incubation with goat anti-rabbit secondary antibodies labeled with 15-nm gold particles diluted 1:50 in PBS, recognizing the bound specific antibodies. Afterward, the grids were washed thoroughly with PBS and then with distilled water and counterstained with 
$1 \%(\mathrm{w} / \mathrm{v})$ uranyl acetate $(\mathrm{pH} 4.3)$ before analysis with a Zeiss EM 10 TEM (Oberkochen, Germany).

\section{RESULTS}

\section{Coexpression of PVX-GFP-2A-CP and TMV-mCherry-2A-CP ${ }_{\mathrm{PVX}}$}

We constructed TMV-based vectors expressing the PVX CP joined to fluorescent proteins mCherry or GFP via a FDMV $2 \mathrm{~A}$ peptide (Figure 1). We used the mCherry-2A-CP $\mathrm{PVX}_{\mathrm{PV}}$ and GFP-2A-CP $P_{\mathrm{PVX}}$ fusions from PVX vectors, which incorporate the mCherry/GFP-2A-CP $\mathrm{P}_{\mathrm{PVX}}$ fusion along with the wt $\mathrm{CP}_{\mathrm{PVx}}$ into the particle, as previously reported (Shukla et al., 2014). These $\mathrm{CP}_{\mathrm{PVX}}$ fusion sequences were cloned into the expression cassette of the TMV-based vector pJL36 (Lindbo, 2007). The resulting vectors (pTMV-mCherry-2A-CP $\mathrm{PVx}_{\mathrm{P}}$ and pTMV-GFP-2A-CP $\mathrm{PVx}_{\text {) }}$ express the PVX CP fusions under the control of an additional heterologous subgenomic promoter-like sequence. Viral vectors were inoculated into plants and coexpressed with a PVX vector expressing the corresponding other fluorescent PVX CP fusion protein.

Plants infected with the individual viral vectors showed systemic infection and overall strong GFP or mCherry expression in the infected leaves, as well as expression of the PVX and TMV CP (Figure 2; Figure S1 in Supplementary Material). The fluorescence intensity was lower with the TMV vectors than the PVX vectors. Coinfections with two vectors based on the same virus (e.g., PVX-GFP-2A-CP and PVX-mCherry-2A-CP) led to the spatial separation of the viruses as they spread through the host plant (Figures 3C,D), and in most cases, one vector became dominant. However, in coinfections with PVX and TMV vectors expressing different $\mathrm{CP}_{\mathrm{PVX}}$ fusions, we observed the coexpression of the different fluorescent proteins in the same parts of the plant (Figures 3A,B). Furthermore, the expression of the PVX-based fluorescent protein was enhanced in coinfections with TMV.

The coexpression of both fluorescent proteins in the same plant cells was confirmed by epifluorescence microscopy (Figure 4). Fluorescent proteins were also transiently expressed as a control by agroinfiltration, using the pTRA vector (Maclean et al., 2007). Plant cells coinfiltrated with both vectors showed simultaneous GFP and mCherry expression, which was confirmed by the yellow color in the overlay picture (Figures $4 \mathrm{~A}-\mathrm{C}$ ). In plants coinfected with two PVX vectors expressing different CP fusions (Figures 4D-F) or TMV vectors (data not shown), no coexpression was observed. Vectors based on the same virus backbones excluded each other, and sharp boundaries for GFP or mCherry expression were noted. In contrast, a combination of TMV- and PVX-based vectors coinfected the same cells, both expressing a PVX CP fusion protein (Figures 4G-I).

SDS-PAGE analyses allowed direct visualization of the fluorescent proteins in gels, and the confirmation of $\mathrm{CP}$ expression in western blots (Figure S1 in Supplementary Material and data not shown). These experiments confirmed the coexpression of different $\mathrm{CP}_{\mathrm{PVX}}$ fusions in the same leaves and the same cells following coinfection with PVX and TMV vectors, but did not reveal the PVX particle composition.

\section{Particle Analysis Presenting Full-Size Fluorescent Proteins}

Virus particles were purified from the coinfected plant material and the particle structure was analyzed to find out whether both fluorescent proteins can be incorporated into the same particles. Following purification, the particle preparations were analyzed by western blot and TEM, using specific antibodies against mCherry

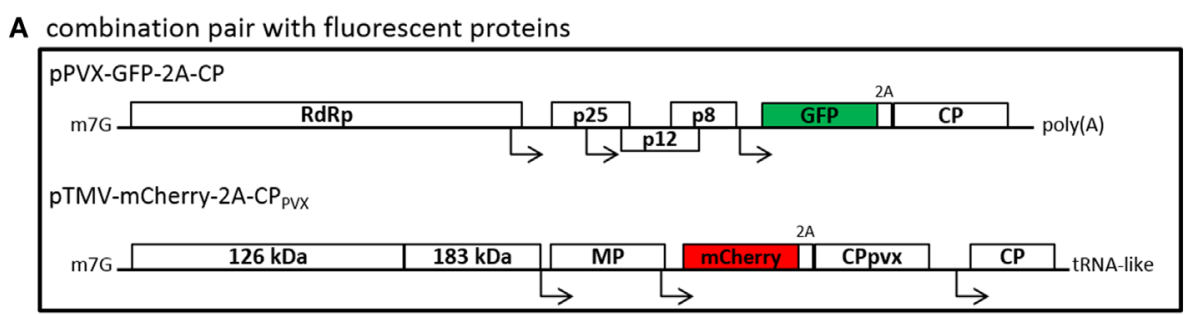

B combination pair with split-mCherry

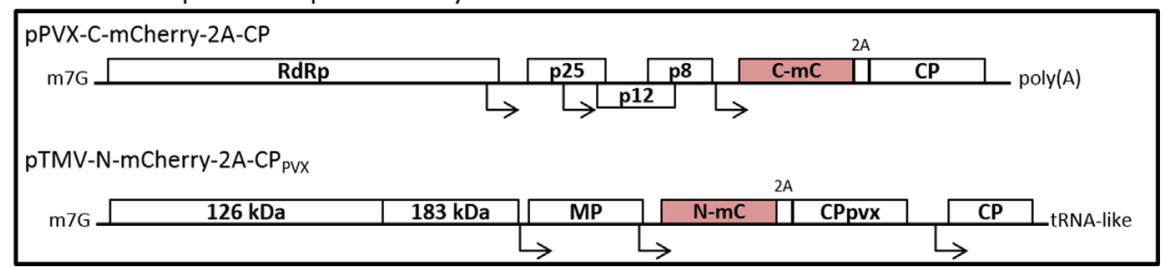

FIGURE 1 | Schematic overview of the used plant viral vectors with fluorescent proteins (A) or split-mCherry (B). (A) PVX-based vectors with fluorescent protein fusions with the help of the 2A sequence of the FDMV are used, as for example the GFP-2A-fusion is shown. The PVX CP fusion was introduced into TMV-based expression vectors, either with mCherry or with GFP. (B) As second option, split-mCherry was used instead of fluorescent proteins. Therefore, either the $\mathrm{N}$ - or $\mathrm{C}$-terminal part of mCherry was cloned into the viral vectors. RdRp, RNA-dependent RNA polymerase; p25, p12, and p8, triple gene block proteins; CP, coat protein; 126 and $183 \mathrm{kDa}$, replicase complex of TMV; MP, movement protein; m7G, methyl guanidine cap; poly(A), polyadenylated tail; tRNA-like, tRNA-like structure of TMV. 


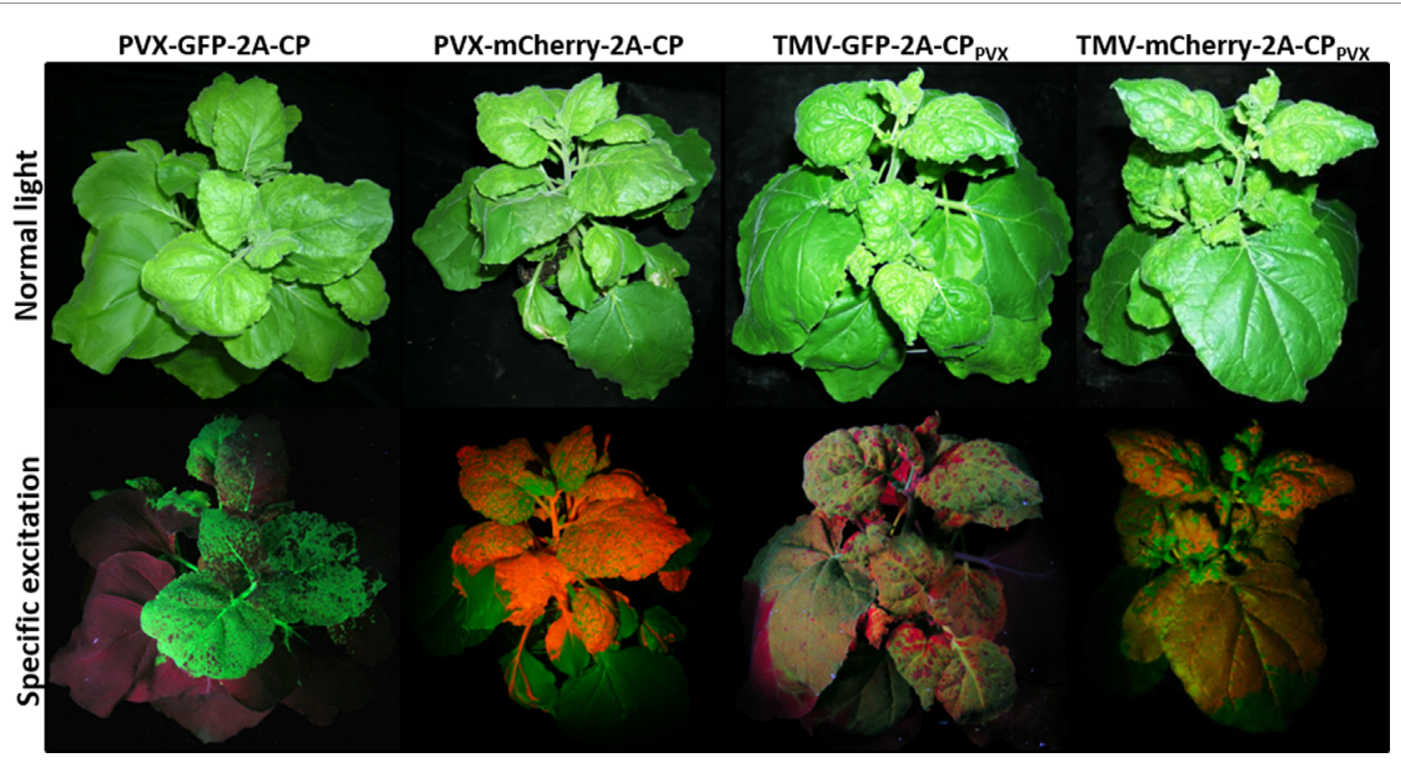

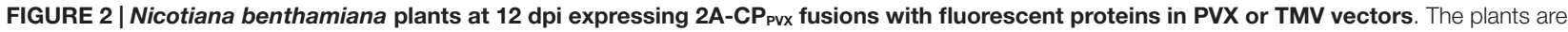
shown under normal light and with specific excitation of the fluorescent proteins. For GFP, the plants are shown under UV light, and for mCherry, they are shown under green light with a red filter.

and GFP. TMV and PVX particles co-accumulated during purification because the process does not separate them. SDS-PAGE revealed the presence of excess TMV particles compared to PVX, with an approximate ratio of 3:1 (Figure S1 in Supplementary Material; Figure 5). Consequently, $1 \mu \mathrm{g}$ of the particle preparation was used for TMV analysis, and $3 \mu \mathrm{g}$ was used for PVX, GFP, and mCherry analysis.

Western blots confirmed the presence of $\mathrm{CP}_{\mathrm{TMV}}(17.5 \mathrm{kDa})$ and $\mathrm{CP}_{\mathrm{PVX}}(25 \mathrm{kDa})$ in the preparation. GFP $(25 \mathrm{kDa})$ was detected in all pooled fractions, but only pooled fraction 2 contained the

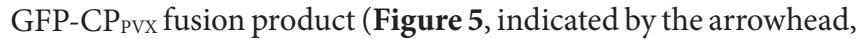
$54 \mathrm{kDa}$ ). Small amounts of the mCherry fusion product were also detected in this fraction using the DsRed antibody $(54 \mathrm{kDa})$. This confirmed the presence of PVX particles with either GFP or mCherry overcoat fusions (Figure 5).

To determine whether both fluorescent protein overcoat structures are found on the same particles, the particles were either directly absorbed to grids for TEM analysis or captured with specific antibodies recognizing the fluorescent proteins or PVX. Control PVX and TMV particles were not captured or labeled with the GFP-specific or DsRed-specific antibodies, confirming the specific binding of these antibodies to the fluorescent proteins (Figure S2 in Supplementary Material). The TMV particles were generally not captured or labeled by the PVX-specific antibody, but a few undecorated particles were found on all grids with TMV. Cross-reactivity of the antibodies against the other fluorescent protein was excluded by purifying either the PVX-GFP-2A-CP or PVX-mCherry-2A-CP particles. Particles displaying a GFP overcoat were only captured and decorated by $\alpha$-GFP, and mCherry overcoat structures were only labeled and captured by $\alpha$-DsRed (Figure S2 in Supplementary Material). In the virus preparation from plants coinfected with PVX-GFP-2A-CP and
TMV-mCherry-2A-CP $\mathrm{PVX}_{\mathrm{P}}$, a mixture of TMV and PVX particles was observed, because the PVX purification process cannot separate these viruses. The TMV particles are shorter $(\sim 300 \mathrm{~nm})$ and have a rigid structure, whereas the PVX particles are $>500 \mathrm{~nm}$ in length and have a flexible structure, thus allowing the particles to be visually distinguished on the grids. Particles from the coexpression were captured and labeled with both the GFP-specific and DsRed-specific antibodies.

The presence of both fluorescent proteins on the surface of PVX particles could be verified by capturing either with the DsRed antibody and labeling with $\alpha$-GFP or vice versa. PVX particles could be captured from the preparations using either of the antibodies, confirming that at least one fluorescent protein can be found on the surface. Furthermore, some of these captured particles were decorated with the antibody against the second fluorescent protein, indicating that both fluorescent protein fusions can indeed assemble into one intact PVX particle (Figure 6).

\section{Coexpression of Split-mCherry-CP $\mathrm{P}_{\mathrm{PVx}}$ Fusions}

We next used the BiFC system with split-mCherry to confirm the assembly of chimeric particles after coexpression of the different PVX CPs. Instead of mCherry and GFP, we used the $\mathrm{N}$ and C-terminal portions of split-mCherry $(\mathrm{N}-\mathrm{mC}$ or $\mathrm{C}-\mathrm{mC})$ as $2 \mathrm{~A}-\mathrm{CP}_{\mathrm{PVX}}$ fusions, and expressed them using either a PVX vector or a TMV vector (Figure 1B). We combined the vectors $\mathrm{PPVX}-\mathrm{N}$ $\mathrm{mC}-2 \mathrm{~A}-\mathrm{CP}$ and $\mathrm{pTMV}-\mathrm{C}-\mathrm{mC}-2 \mathrm{~A}-\mathrm{CP}_{\mathrm{PVx}}$ or pPVX-C-mC-2A-CP

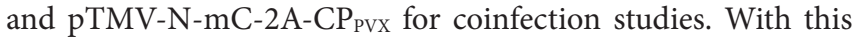
system, red fluorescence would only be generated if both parts of the split-mCherry CP fusions are expressed in the same cells and interact with each other. 


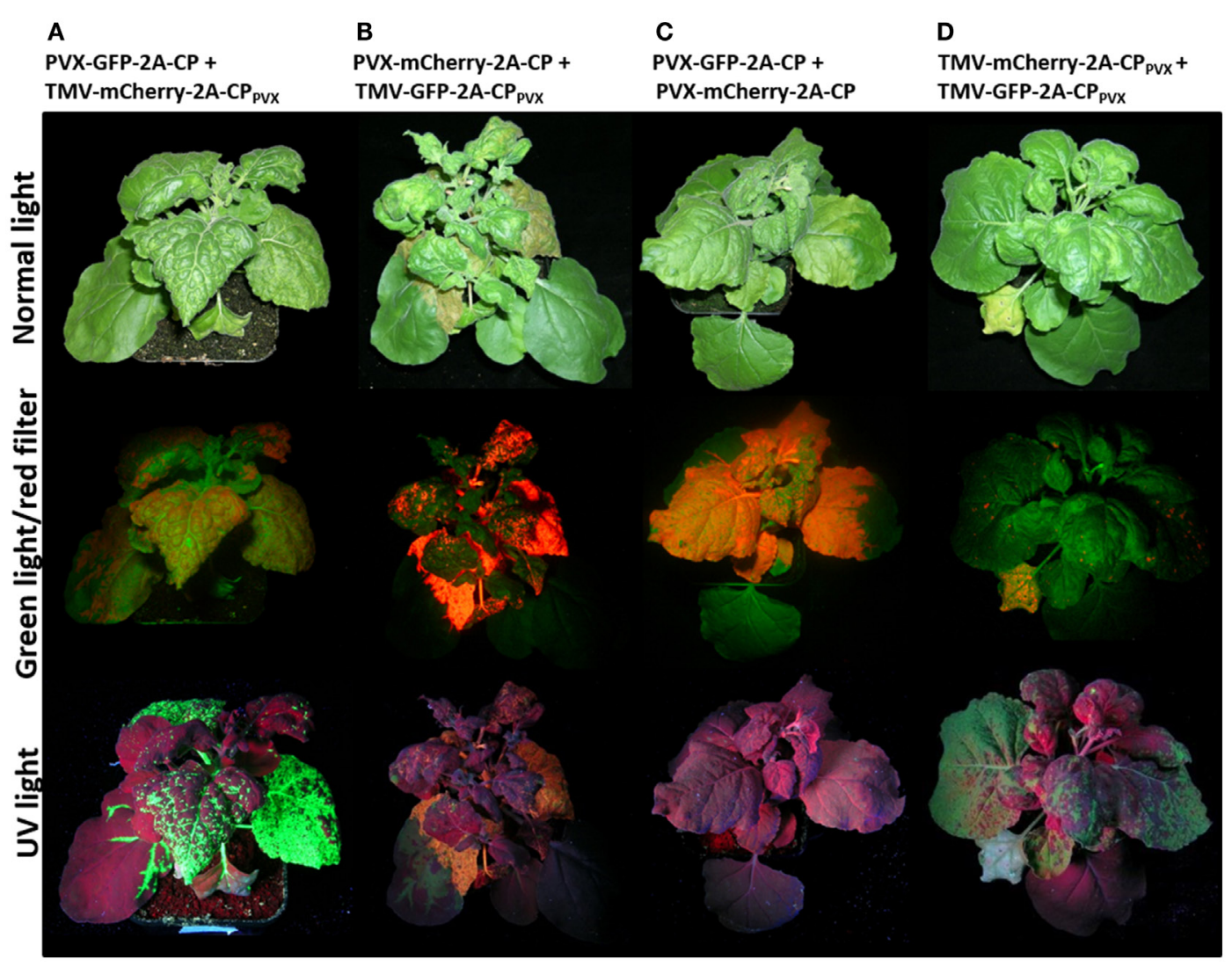

FIGURE 3 | Nicotiana benthamiana plants coinfected with PVX and TMV vectors expressing CP fusions of PVX at 12 dpi displayed as whole plant. Plants were coinfected with (A) PVX-GFP-2A-CP and TMV-mCherry-2A-CPPVx, (B) PVX-mCherry-2A-CP and TMV-GFP-2A-CPpvx, (C) PVX-GFP-2A-CP and PVX-mCherry-2A-CP, and (D) TMV-mCherry-2A-CP PVx and TMV-GFP-2A-CP PVx. The plants are shown under normal light and with excitation of the fluorescent proteins (UV light for GFP and green light with a red filter for mCherry).

Plants were infected with each construct alone and pairwise combinations. No fluorescence was detected in single infections, or coinfections with two PVX- or TMV-based vectors expressing the different split-mCherry parts (Figures 7A-D and data not shown). Expression of the split-mCherry-2A-CP $\mathrm{PVX}_{\mathrm{P}}$ was confirmed by immunocapture RT-PCR and western blot analysis (Figures S3 and S5 in Supplementary Material). In plants coinfected with a combination of PVX and TMV vectors expressing different parts of the split-mCherry, only weak fluorescence was observed in infected leaves and was confirmed by fluorescence microscopy in the cells (Figures 7E-F). In all infections, the combination of the C-terminal part of the split-mCherry expressed from the PVX vector and the $\mathrm{N}$-terminal part expressed from the TMV vector gave more intense red fluorescence than the reciprocal arrangement.

The split-mCherry data confirmed the coexpression of the two different viral vectors in a single cell, but we could not rule out the possibility that interactions might occur free in the cytosol, e.g., as CP dimers rather than in the context of an assembled particle. Therefore, particles were purified from infections with PVX-N-mC-2A-CP, PVX-C-mC-2A-CP and coinfections with a TMV vector expressing the other portion of split-mCherry, respectively. During purification via sucrose gradients, we obtained fractions (16-20) of the purified particles showing red fluorescence (Figure S4 in Supplementary Material). This indicated that the split-mCherry components may be able to form a functional fluorescent protein on the particle surface. We used TEM to determine whether the DsRed antibody could detect the split parts of mCherry even though the antibody could not detect the split-mCherry parts in western blot (Figure S5 in Supplementary Material). The adsorption grids showed again a mixture of TMV and PVX particles with an approximate ratio of 3:1 (Figures 8B,C). PVX particles were either captured with the DsRed antibody and labeled after capture with the PVX antibody or vice versa. We were unable to capture particles of the PVX control and particles displaying only one split-mCherry component by the DsRed antibody or label particles after capture with $\alpha$-PVX when using the DsRed antibody. This confirmed that the DsRed antibody can only detect the complete mCherry protein and not the individual split components (Figure 8; Figure S5 in Supplementary Material). However, we were able to capture PVX particles from preparations derived from virus coinfections using the same $\alpha$-DsRed antibody in both coexpressions of the split mCherry CP fusions. Furthermore, we were 


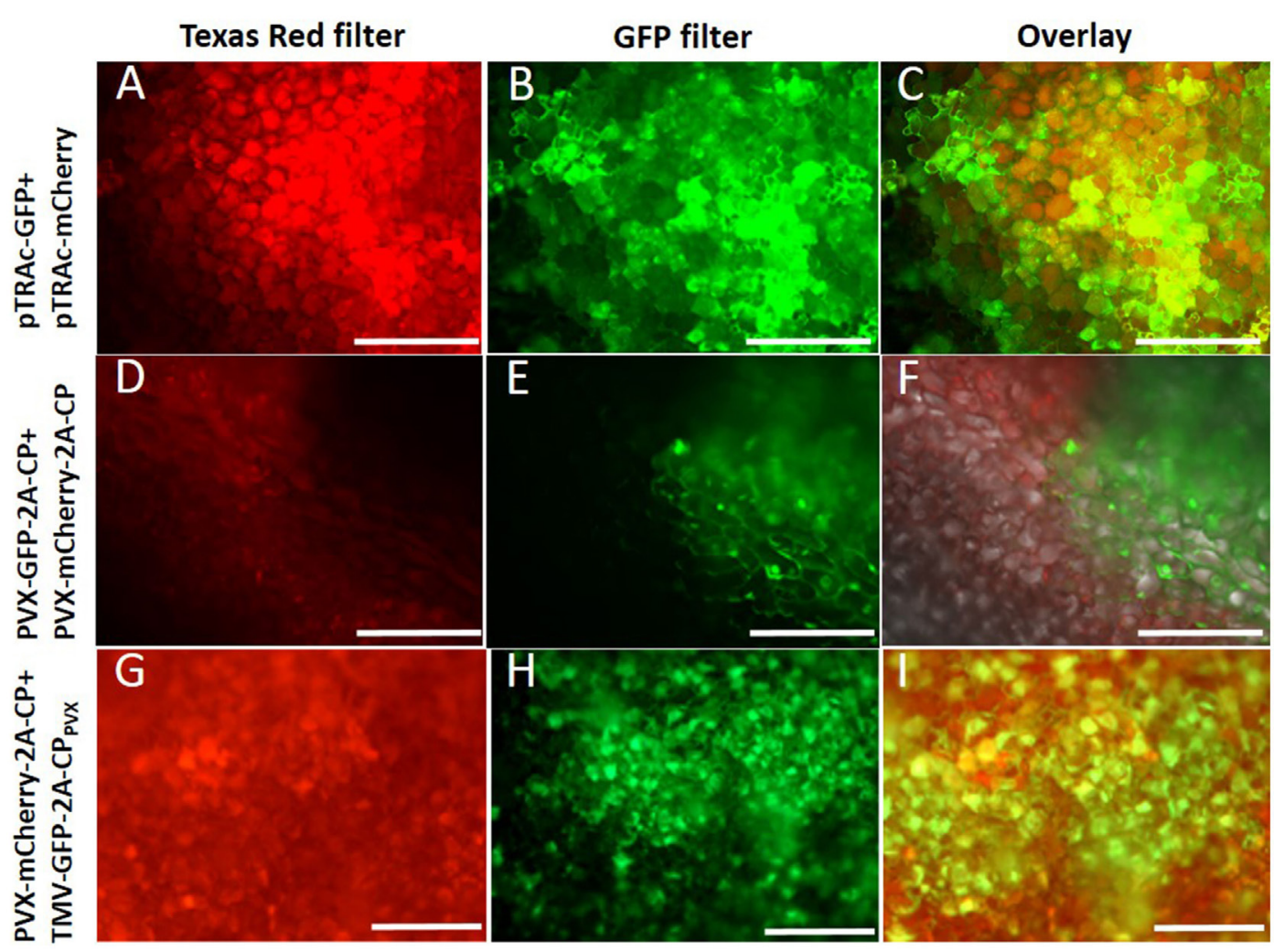

FIGURE 4 | Plant cells were analyzed by fluorescence microscopy with a 10x magnification. (A-C) Coexpression of GFP and mCherry with pTRAC vectors (positive control), (D-F) coinfection with PVX-GFP-2A-CP and PVX-mCherry-CP, (G-I) coinfection of PVX-mCherry-2A-CP and TMV-GFP-2A-CP, shown with excitation of mCherry (Texas red filter), (B,E,H) cells shown with GFP excitation, (C,F,I) overlay of the pictures for the shown coexpression.

able to label the particles with the DsRed-specific antibody after capturing the particles with the PVX antibody from the PVX/ TMV mixture (Figures $\mathbf{8 H}, \mathbf{I}$ ). We observed a better labeling with the $\alpha$-DsRed antibody in particles derived from the coinfection if the C-terminal split-mCherry part is expressed by PVX. The detection of functional mCherry on the particle surface proves the assembly of hybrid chimeric PVX particles.

\section{DISCUSSION}

We have developed a novel production system for hybrid chimeric virus particles with at least two different polypeptides presented on the surface. With help of the FDMV 2A sequence, we were able to display rather large proteins on the recombinant particle (the fluorescent proteins GFP and mCherry), and also displayed the two split-mCherry portions, which interacted on the particle surface.

\section{Coexpression of Two CP $\mathrm{Pvx}_{\mathrm{P}}$ Fusion Proteins Using PVX- and TMV-Based Vectors}

We could show that a full-size PVX expression vector accepts the coexpression of additional PVX CP fusion protein delivered by a different viral expression vector. We found that PVX expression is enhanced in the presence of the TMV vector, resulting in brighter fluorescence for the PVX multiplication expressed fluorescent protein (Figure 3, mCherry fluorescence in Figure 3B compared to Figure 3C). The enhancement of PVX in a TMV-PVX coinfection is well known (Goodman and Ross, 1974) and was also observed in our system.

The fluorescence intensity of both proteins delivered by the TMV vectors was always lower than those delivered by the PVX vectors, although TMV accumulated to higher titers. This can possibly be explained by the distance of the fluorescent protein sequence relative to the $3^{\prime}$-end of the TMV genome (Culver et al., 1993). The distance between the genes for GFP or mCherry and the $3^{\prime}$-end is increased by the additional $\mathrm{CP}_{\mathrm{PVx}}$ sequence, which limits the expression of the fluorescent protein. If the same fluorescent protein is expressed alone by the TMV vector, much more intense fluorescence and expression is observed (Lindbo, 2007). The influence of the relative distance of the gene of interest from the 3 '-end of viral genomes could be explained by the impact of non-sense-mediated decay (NMD). In a recent study, it could be shown that long 3 '-untranslated regions in subgenomic RNAs resulting from gene insertions into PVX vectors trigger the intrinsic restriction pathway in plants for plus-sense RNA viruses, namely NMD (Garcia et al., 2014). We speculate that 


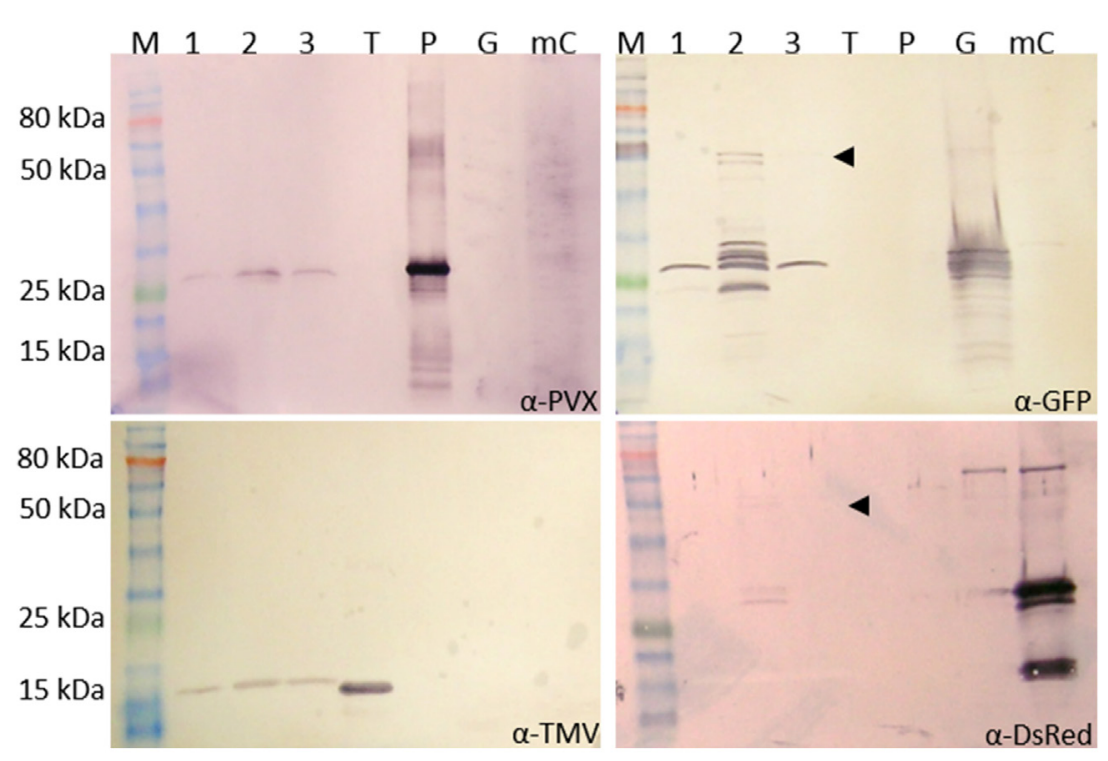

FIGURE 5 | Analysis of purified PVX and TMV particles with GFP-2A-CPPvx and mCherry-2A-CP ${ }_{p v x}$ fusions. The particles were purified from a PVX-GFP2A-CP plus TMV-mCherry-2A-CP PVX coinfection and the preparation was analyzed by western blot to detect CPPVX $(\alpha-P V X), C P_{\text {TMV }}(\alpha-T M V)$, GFP $(\alpha-G F P)$, and mCherry ( $\alpha$-DsRed) using GAR AP as the secondary antibody. M: P7711S protein ladder (NEB), 1-3: different pooled fractions of the preparation, T: purified TMV particles $(0.5 \mu \mathrm{g})$, P: purified PVX particles $(0.5 \mu \mathrm{g})$, G: GFP control (plant sap expressing GFP from a pTRAc vector), mC: mCherry control (plant sap expressing mCherry from a pTRAc vector). For PVX, GFP, and mCherry, $3 \mu \mathrm{g}$ of the particle mixture was separated by SDS-PAGE. Only $1 \mu \mathrm{g}$ was used for TMV analysis. The pooled fraction 2 was analyzed in TEM (Figure 6). The same amount of purified particles (10 $\mu \mathrm{g})$ was used for the grids.

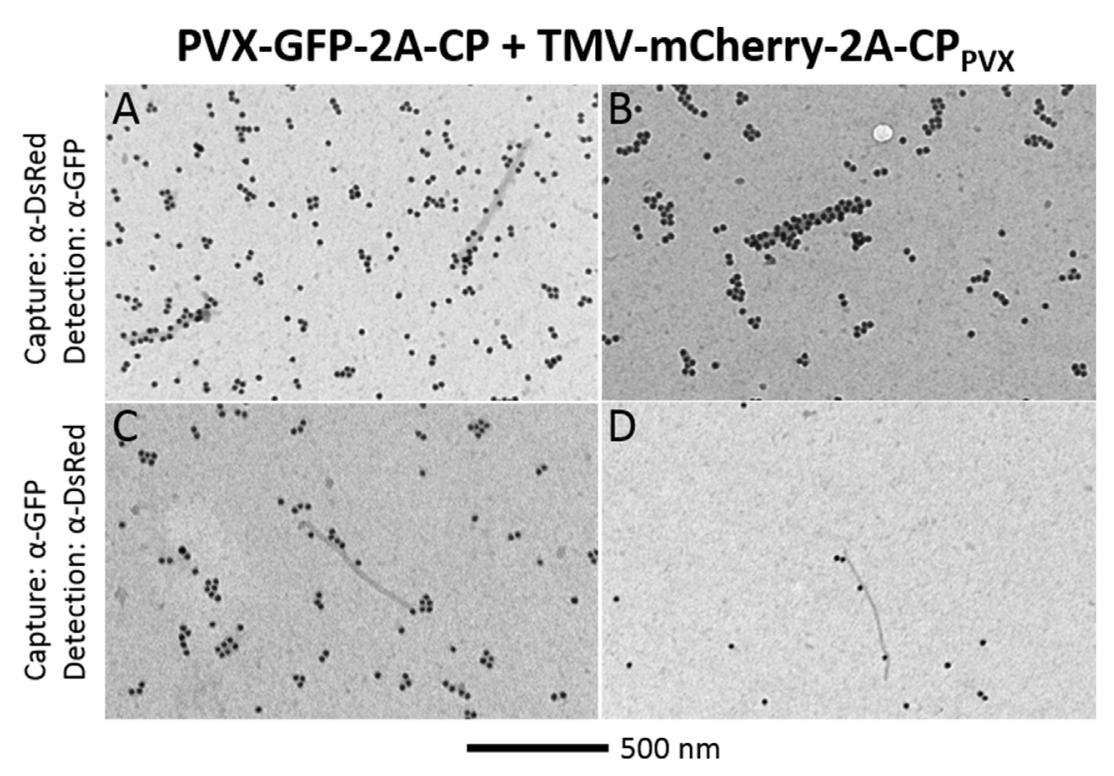

FIGURE 6 | TEM analysis of chimeric PVX particles displaying GFP and mCherry overcoat structures. After coinfection with PVX-GFP-2A-CP and TMV-mCherry-2A-CP PVx, particles were captured with $\alpha$-DsRed and decorated with $\alpha$-GFP $\mathbf{( A , B )}$, or captured with $\alpha$-GFP and decorated with $\alpha$-DsRed $(\mathbf{C}, \mathbf{D})$. $\mathrm{Bar}=500 \mathrm{~nm}$.

this phenomenon might also explain why the genes located at the veriest $3^{\prime}$-end of viral genomes with $3^{\prime}$-coterminal subgenomic RNAs is in most cases expressed strongest. Thus, alternative expression strategies, e.g., 2A ribosomal skip sequences (Cruz et al., 1996; Gopinath et al., 2000), internal ribosome entry sites (Toth et al., 2001), or stop codon suppression (Hamamoto et al., 


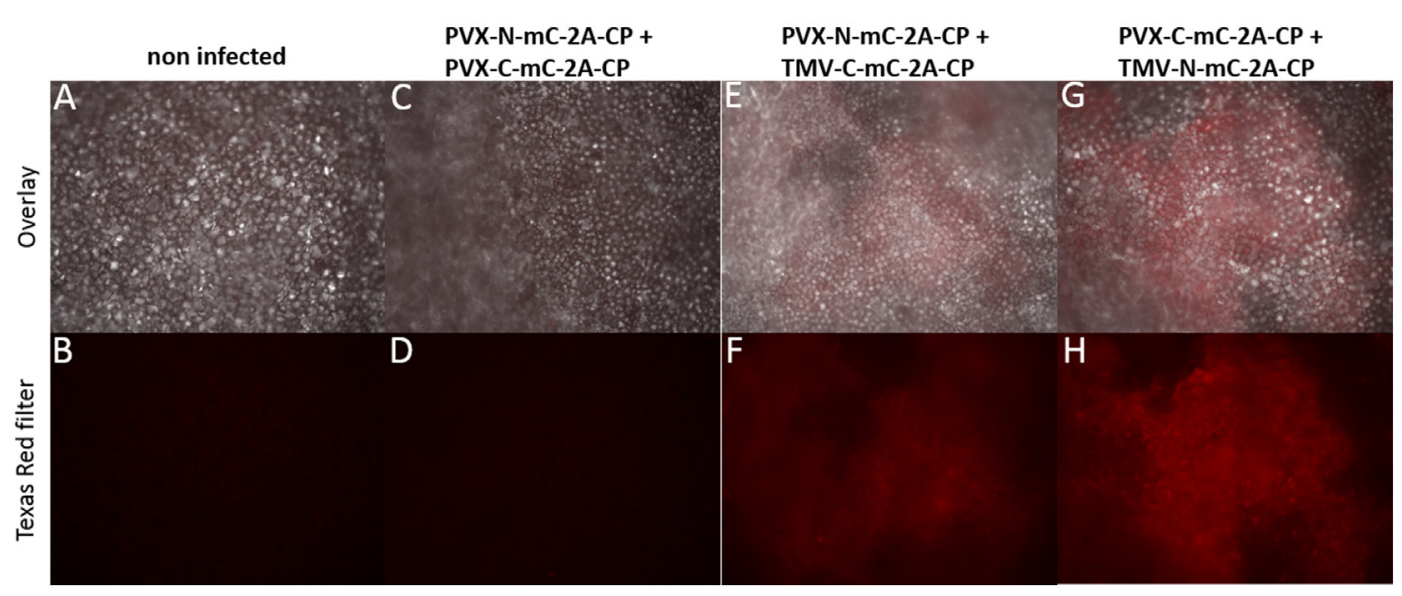

FIGURE 7 | Nicotiana benthamiana cells analyzed for red fluorescence resulting from interactions of split-mCherry at $\mathbf{1 4}$ dpi. Cells are shown in $10 \times$ magnification and specific excitation for mCherry was applied with a Texas Red filter (B,D,F,H). The upper pictures show the overlay of transmitted light and the specific fluorescence excitation (A,C,E,G). (A,B) N. benthamiana non-infected, (C,D) plant infected with PVX-C-mC-2A-CP and PVX-N-mC-2A-CP, (E,F) coinfection of PVX-N-mC-2A-CP and TMV-C-mC-2A-CP PVx, and $\mathbf{( G , H ) ~ c o i n f e c t i o n ~ o f ~ P V X - C - m C - 2 A - C P ~ a n d ~ T M V - N - m C - 2 A - C P P V x . ~}$

1993) could be advantageous. In PVX vectors, it can be observed that expression via a $2 \mathrm{~A}$-sequence fusion (this study and Cruz et al., 1996; Shukla et al., 2014) yield better results compared to an additional subgenomic promoter-like sequence (Baulcombe et al., 1995; Dickmeis et al., 2014).

Because coexpression of PVX CPs with different viral vectors was possible in the same cells, it was interesting to find out whether hybrid chimeric particles would be generated as well. We have identified PVX particles with different foreign PVX CP fusions assembled into the virion structure (Figure 6; Figure S2 in Supplementary Material), thus confirming the construction of chimeric PVX particles with a hybrid GFP and mCherry overcoat structure. This shows that PVX CP delivered by TMV can interact with PVX genomic RNA, giving initial hints that virion formation is not strictly coupled to CP production.

\section{Bimolecular Fluorescence Complementation}

To analyze our expression system in more detail, we used the mCherry BiFC components (Fan et al., 2008) as fusion proteins in our PVX overcoat system. The BiFC system allows the analysis of protein interactions in vivo by fusing different parts of a fluorescent protein to the target proteins (Kodama and Wada, 2009). The fluorescent proteins are split and fluorescence can only be restored through the interaction of the target proteins. Plant viral CPs known to assemble without RNA were transiently expressed by A. tumefaciens for the evaluation of a monomeric red fluorescent protein (mRFP)-based BiFC system, because of their definite interaction capacity (Zilian and Maiss, 2011). The CPs of TMV, Plum pox virus (PPV), and capsicum chlorosis virus $(\mathrm{CaCV})$ were shown to interact in the plant cells with itself after transient expression and by direct fusions of the split-mRFP portions to the CPs or a 7 amino acid linker sequence in between; however, full-sized particle formation has not been investigated.
We used split-mCherry to confirm the coexpression of two viral vectors in the same cells. Restoration of the red fluorescence showed the coexpression of the two different PVX CP fusion proteins (Figure 7). Still, mCherry fluorescence does not necessarily confirm the interaction of the split-mCherry components during particle assembly, which may be explained by low potential interaction of free split-mCherry components (Morell et al., 2007) by the formation of CP dimers and oligomers.

We then analyzed the purified particles for the presence of mCherry restored from the split components. PVX particles displaying only one split-mCherry component were not labeled by the $\alpha$-DsRed antibody, whereas some particles derived from the coexpression with the TMV/PVX combination were either captured or labeled by the DsRed antibody (Figure 8). Interestingly, we obtained a better labeling with the $\alpha$-DsRed antibody if the C-terminal split-mCherry is expressed by the PVX vector, indicating a higher amount of particles with restored mCherry. The $9-\mathrm{kDa}$ C-terminal split-mCherry is the smaller part of the mCherry protein $(27 \mathrm{kDa})$. Thus, it seems to be more favorable for the construction of hybrid chimeric PVX particles to express the smaller peptide in the context of the PVX vector.

We have developed a plant expression system for the production of novel hybrid chimeric PVX particles, presenting two different overcoats on the surface. The PVX virion is a suitable epitope presentation system with $1270 \mathrm{CP}$ subunits comprising each particle, thus a well-defined number of epitopes can be presented in high density to the immune system. PVX has been used successfully to present different epitopes and trigger an efficient immune response in animal models (Marusic et al., 2001; Lico et al., 2006). However, only single tandem repeats of epitopes have been presented on PVX as CP fusions (Uhde-Holzem et al., 2010). With our system, at least two different epitopes or even more in combinations with tandem repeats can be presented on the particle surface. We proved the system with fluorescent 


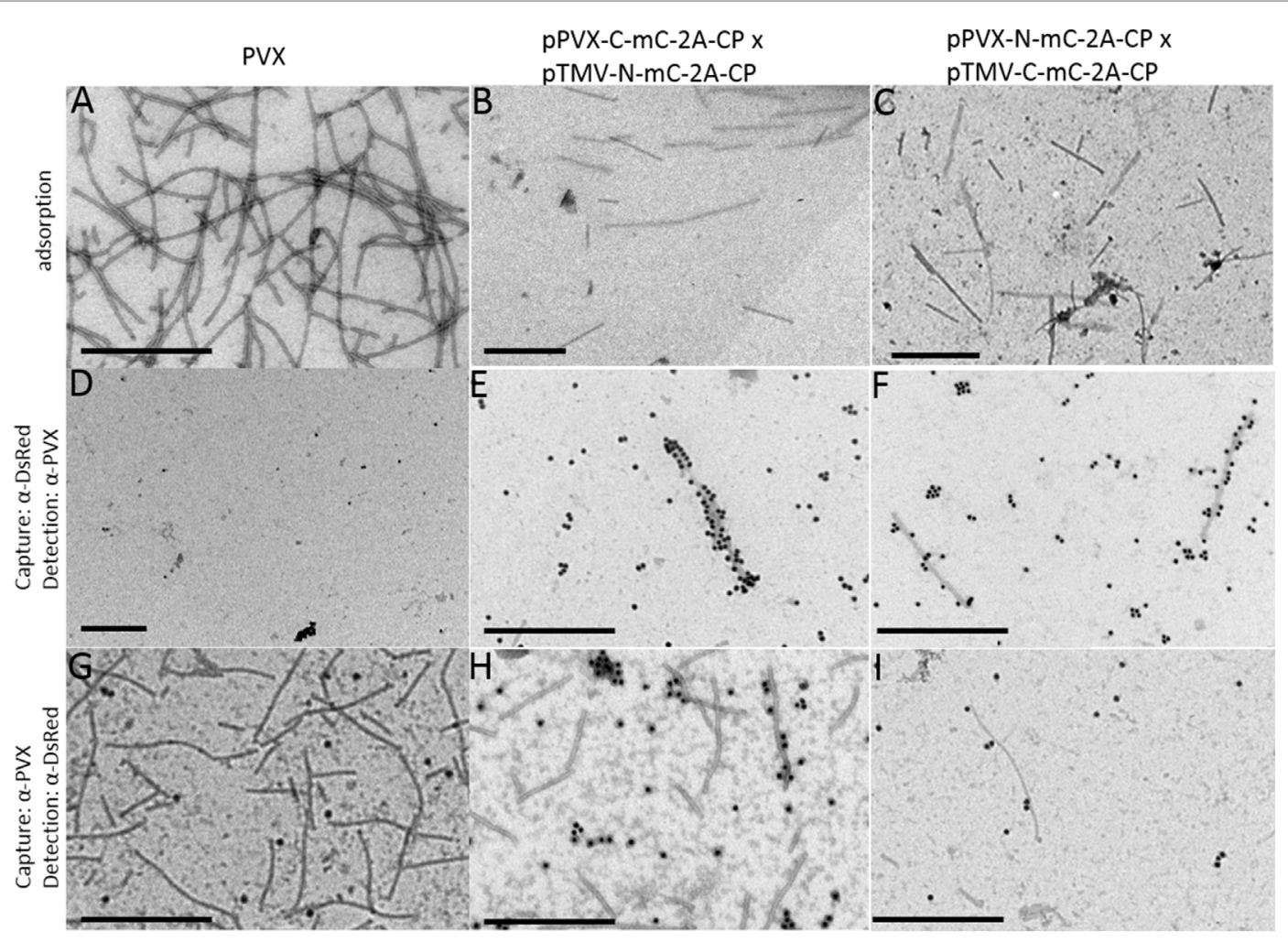

FIGURE 8 | Analysis of purified PVX particles in TEM studies with split-mCherry. For TEM analysis of the particles, the preparations were either directly adsorbed to the grids (A-C) or captured with a DsRed-specific antibody and labeled with a PVX-specific antibody with GAR15nm (D-F) or captured with a PVX-specific antibody and labeled with a DsRed-specific antibody with GAR15nm (G-I). PVX purification was used as control (A,D,G), the purification of the coinfection of PVX-C-mC-2A-CP and TMV-N-mC-2A-CP PVx (B,E,H), and the coinfection of PVX-N-mC-2A-CP and TMV-C-mC-2A-CPPVx (C,F,I) are displayed. Bars $=500 \mathrm{~nm}$

proteins, to directly visualize the expression of a second PVX CP in planta by another viral vector. We utilized the $2 \mathrm{~A}$ sequence to obtain a hybrid overcoat structure on the PVX particles with the fluorescent proteins because these large proteins would impair particle assembly as a direct fusion. For epitope presentation, the epicoat structure with a particle completely decorated with epitopes would be more favorable.

During particle purification, TMV particles derived from the expression system were isolated as well (i.e., Figures $\mathbf{5}$ and 6). Thus, with a supplementary presentation of epitopes on the TMV particle surface, an even stronger vaccine candidate might be created. In all our particle purifications, we observed a ratio of TMV and PVX particles of $\sim 3: 1$. The system, therefore, offers an additional possibility for tuning epitope presentation. Depending on the target pathogens, epitopes that induce a comparably low immune response can be presented on the TMV particles (which generate the largest number of purified particles in the mixture) and the comparably stronger epitopes can be displayed on PVX particles. The advantage of the coexpression is an easy purification of both rod-shaped particles in one procedure. Thus, our system provides a novel alternative expression platform for multicomponent/epitope immunization.

\section{AUTHOR CONTRIBUTIONS}

UC and CD provided the idea of the work and designed the experiments. CD conducted the experiments regarding the coexpression with the full-sized fluorescent proteins, whereas $\mathrm{MH}$ conducted the experiments with the split-mCherry constructs. $\mathrm{UC}, \mathrm{CD}, \mathrm{MH}$, and RF participated in the interpretation of results and critically reviewed the manuscript. CD wrote the paper. All authors read and approved the final manuscript.

\section{ACKNOWLEDGMENTS}

We thank Karolin Richter for excellent technical assistance and Dr. John Lindbo for the kind gift of the TMV vector pJL36. This research was supported by the scholarship for supporting young scientists of the RWTH Aachen University (Stipendium nach den Richtlinien zur Förderung des wissenschaftlichen Nachwuchses der RWTH Aachen University).

\section{SUPPLEMENTARY MATERIAL}

The Supplementary Material for this article can be found online at http://journal.frontiersin.org/article/10.3389/fbioe.2015.00189 


\section{REFERENCES}

Adams, M. J., Antoniw, J. F., Bar-Joseph, M., Brunt, A. A., Candresse, T., Foster, G. D., et al. (2004). The new plant virus family Flexiviridae and assessment of molecular criteria for species demarcation. Arch. Virol. 149, 1045-1060. doi:10.1007/s00705-004-0304-0

Angell, S. M., and Baulcombe, D. C. (1997). Consistent gene silencing in transgenic plants expressing a replicating potato virus X RNA. EMBO J. 16, 3675-3684. doi:10.1093/emboj/16.12.3675

Atabekov, J., Dobrov, E., Karpova, O., and Rodionova, N. (2007). Potato virus X: structure, disassembly and reconstitution. Mol. Plant Pathol. 8, 667-675. doi:10.1111/j.1364-3703.2007.00420.x

Awram, P., Gardner, R. C., Forster, R. L., and Bellamy, A. R. (2002). The potential of plant viral vectors and transgenic plants for subunit vaccine production. Adv. Virus Res. 58, 81-124. doi:10.1016/S0065-3527(02)58003-9

Baratova, L. A., Grebenshchikov, N. I., Shishkov, A. V., Kashirin, I. A., Radavsky, J. L., Jarvekulg, L., et al. (1992). The topography of the surface of potato virus $\mathrm{X}$ : tritium planigraphy and immunological analysis. J. Gen. Virol. 73(Pt 2), 229-235. doi:10.1099/0022-1317-73-2-229

Baulcombe, D. C., Chapman, S., and Santa Cruz, S. (1995). Jellyfish green fluorescent protein as a reporter for virus infections. Plant J. 7, 1045-1053. doi:10.1046/j.1365-313X.1995.07061045.x

Beck, D. L., Guilford, P. J., Voot, D. M., Andersen, M. T., and Forster, R. L. (1991). Triple gene block proteins of white clover mosaic potexvirus are required for transport. Virology 183, 695-702. doi:10.1016/0042-6822(91)90998-Q

Brennan, F. R., Jones, T. D., and Hamilton, W. D. (2001). Cowpea mosaic virus as a vaccine carrier of heterologous antigens. Mol. Biotechnol. 17, 15-26. doi:10.1385/MB:17:1:15

Chapman, S., Kavanagh, T., and Baulcombe, D. (1992). Potato virus X as a vector for gene expression in plants. Plant J. 2, 549-557. doi:10.1046/j.1365-313X.1992. t01-24-00999.x

Chatterji, A., Ochoa, W. F., Ueno, T., Lin, T., and Johnson, J. E. (2005). A virusbased nanoblock with tunable electrostatic properties. Nano Lett. 5, 597-602. doi:10.1021/nl048007s

Cruz, S. S., Chapman, S., Roberts, A. G., Roberts, I. M., Prior, D. A., and Oparka, K. J. (1996). Assembly and movement of a plant virus carrying a green fluorescent protein overcoat. Proc. Natl. Acad. Sci. U.S.A. 93, 6286-6290. doi:10.1073/ pnas.93.13.6286

Cruz, S. S., Roberts, A. G., Prior, D. A., Chapman, S., and Oparka, K. J. (1998). Cellto-cell and phloem-mediated transport of potato virus $\mathrm{X}$. The role of virions. Plant Cell 10, 495-510. doi:10.2307/3870728

Culver, J. N., Lehto, K., Close, S. M., Hilf, M. E., and Dawson, W. O. (1993). Genomic position affects the expression of tobacco mosaic virus movement and coat protein genes. Proc. Natl. Acad. Sci. U.S.A. 90, 2055-2059. doi:10.1073/ pnas.90.5.2055

Dickmeis, C., Fischer, R., and Commandeur, U. (2014). Potato virus X-based expression vectors are stabilized for long-term production of proteins and larger inserts. Biotechnol. J. 9, 1369-1379. doi:10.1002/biot.201400347

Donnelly, M. L., Hughes, L. E., Luke, G., Mendoza, H., Ten Dam, E., Gani, D., et al. (2001a). The 'cleavage' activities of foot-and-mouth disease virus $2 \mathrm{~A}$ site-directed mutants and naturally occurring '2A-like' sequences. J. Gen. Virol. 82, 1027-1041. doi:10.1099/0022-1317-82-5-1027

Donnelly, M. L., Luke, G., Mehrotra, A., Li, X., Hughes, L. E., Gani, D., et al. (2001b). Analysis of the aphthovirus $2 \mathrm{~A} / 2 \mathrm{~B}$ polyprotein 'cleavage' mechanism indicates not a proteolytic reaction, but a novel translational effect: a putative ribosomal 'skip'. J. Gen. Virol. 82, 1013-1025. doi:10.1099/0022-1317-82-5-1013

Draghici, H. K., Pilot, R., Thiel, H., and Varrelmann, M. (2009). Functional mapping of PVX RNA-dependent RNA-replicase using pentapeptide scanning mutagenesis-Identification of regions essential for replication and subgenomic RNA amplification. Virus Res. 143, 114-124. doi:10.1016/j. virusres.2009.03.013

Fan, J. Y., Cui, Z. Q., Wei, H. P., Zhang, Z. P., Zhou, Y. F., Wang, Y. P., et al. (2008). Split mCherry as a new red bimolecular fluorescence complementation system for visualizing protein-protein interactions in living cells. Biochem. Biophys. Res. Commun. 367, 47-53. doi:10.1016/j.bbrc.2007.12.101

Fischer, R., Schillberg, S., Hellwig, S., Twyman, R. M., and Drossard, J. (2012). GMP issues for recombinant plant-derived pharmaceutical proteins. Biotechnol. Adv. 30, 434-439. doi:10.1016/j.biotechadv.2011.08.007
Garcia, D., Garcia, S., and Voinnet, O. (2014). Nonsense-mediated decay serves as a general viral restriction mechanism in plants. Cell Host Microbe 16, 391-402. doi:10.1016/j.chom.2014.08.001

Giritch, A., Marillonnet, S., Engler, C., Van Eldik, G., Botterman, J., Klimyuk, V., et al. (2006). Rapid high-yield expression of full-size IgG antibodies in plants coinfected with noncompeting viral vectors. Proc. Natl. Acad. Sci. U.S.A. 103, 14701-14706. doi:10.1073/pnas.0606631103

Gonzalez, M. J., Plummer, E. M., Rae, C. S., and Manchester, M. (2009). Interaction of Cowpea mosaic virus (CPMV) nanoparticles with antigen presenting cells in vitro and in vivo. PLoS ONE 4:e7981. doi:10.1371/journal.pone.0007981

Goodman, R. M., and Ross, A. F. (1974). Enhancement of potato virus X synthesis in doubly infected tobacco occurs in doubly infected cells. Virology 58, 16-24. doi:10.1016/0042-6822(74)90160-3

Gopinath, K., Wellink, J., Porta, C., Taylor, K. M., Lomonossoff, G. P., and Van Kammen, A. (2000). Engineering cowpea mosaic virus RNA-2 into a vector to express heterologous proteins in plants. Virology 267, 159-173. doi:10.1006/ viro.1999.0126

Hamamoto, H., Sugiyama, Y., Nakagawa, N., Hashida, E., Matsunaga, Y., Takemoto, S., et al. (1993). A new tobacco mosaic virus vector and its use for the systemic production of angiotensin-I-converting enzyme inhibitor in transgenic tobacco and tomato. Biotechnology (N Y) 11, 930-932. doi:10.1038/nbt0893-930

Hayashi, J., Aoki, H., Arakawa, Y., and Hino, O. (1999). Hepatitis C virus and hepatocarcinogenesis. Intervirology 42, 205-210. doi:10.1159/000024962

Hefferon, K. (2013). Plant-derived pharmaceuticals for the developing world. Biotechnol. J. 8, 1193-1202. doi:10.1002/biot.201300162

Johnson, J., Lin, T., and Lomonossoff, G. (1997). Presentation of heterologous peptides on plant viruses: genetics, structure, and function. Annu. Rev. Phytopathol. 35, 67-86. doi:10.1146/annurev.phyto.35.1.67

Kim, K. H., and Hemenway, C. (1997). Mutations that alter a conserved element upstream of the potato virus X triple block and coat protein genes affect subgenomic RNA accumulation. Virology 232, 187-197. doi:10.1006/viro.1997.8565

Kodama, Y., and Wada, M. (2009). Simultaneous visualization of two protein complexes in a single plant cell using multicolor fluorescence complementation analysis. Plant Mol. Biol. 70, 211-217. doi:10.1007/s11103-009-9467-0

Koenig, R. (1971). Nucleic acids in the potato virus X group and in some other plant viruses: comparison of the molecular weights by electrophoresis in acrylamide-agarose composite gels. J. Gen. Virol. 10, 111-114. doi:10.1099/0022-1317-10-1-111

Koenig, R., and Torrance, L. (1986). Antigenic analysis of potato virus-X by means of monoclonal-antibodies. J Gen Virol 67, 2145-2151. doi:10.1099/0022-1317-67-10-2145

Koonin, E. V. (1991). The phylogeny of RNA-dependent RNA polymerases of positive-strand RNA viruses. J. Gen. Virol. 72(Pt 9), 2197-2206. doi:10.1099/0022-1317-72-9-2197

Laemmli, U. K. (1970). Cleavage of structural proteins during the assembly of the head of bacteriophage T4. Nature 227, 680-685. doi:10.1038/227680a0

Lee, K. L., Uhde-Holzem, K., Fischer, R., Commandeur, U., and Steinmetz, N. F. (2014). Genetic engineering and chemical conjugation of potato virus X. Methods Mol. Biol. 1108, 3-21. doi:10.1007/978-1-62703-751-8_1

Lico, C., Capuano, F., Renzone, G., Donini, M., Marusic, C., Scaloni, A., et al. (2006) Peptide display on Potato virus X: molecular features of the coat protein-fused peptide affecting cell-to-cell and phloem movement of chimeric virus particles. J. Gen. Virol. 87, 3103-3112. doi:10.1099/vir.0.82097-0

Lico, C., Mancini, C., Italiani, P., Betti, C., Boraschi, D., Benvenuto, E., et al. (2009). Plant-produced potato virus $\mathrm{X}$ chimeric particles displaying an influenza virus-derived peptide activate specific CD8+ $\mathrm{T}$ cells in mice. Vaccine 27, 5069-5076. doi:10.1016/j.vaccine.2009.06.045

Lico, C., Santi, L., Twyman, R. M., Pezzotti, M., and Avesani, L. (2012). The use of plants for the production of therapeutic human peptides. Plant Cell Rep. 31, 439-451. doi:10.1007/s00299-011-1215-7

Lindbo, J. A. (2007). High-efficiency protein expression in plants from agroinfection-compatible Tobacco mosaic virus expression vectors. BMC Biotechnol. 7:52. doi:10.1186/1472-6750-7-52

Linnik, O., Liesche, J., Tilsner, J., and Oparka, K. J. (2013). Unraveling the structure of viral replication complexes at super-resolution. Front. Plant Sci. 4:6. doi:10.3389/fpls.2013.00006

Lomonossoff, G. P., and Evans, D. J. (2014). Applications of plant viruses in bionanotechnology. Curr. Top. Microbiol. Immunol. 375, 61-87. 
Ma, J. K., Barros, E., Bock, R., Christou, P., Dale, P. J., Dix, P. J., et al. (2005a). Molecular farming for new drugs and vaccines. Current perspectives on the production of pharmaceuticals in transgenic plants. EMBO Rep. 6, 593-599. doi:10.1038/sj.embor.7400470

Ma, J. K., Chikwamba, R., Sparrow, P., Fischer, R., Mahoney, R., and Twyman, R. M. (2005b). Plant-derived pharmaceuticals - the road forward. Trends Plant Sci. 10, 580-585. doi:10.1016/j.tplants.2005.10.009

Maclean, J., Koekemoer, M., Olivier, A. J., Stewart, D., Hitzeroth, I. I., Rademacher, T., et al. (2007). Optimization of human papillomavirus type 16 (HPV-16) L1 expression in plants: comparison of the suitability of different HPV-16 L1 gene variants and different cell-compartment localization. J. Gen. Virol. 88, 1460-1469. doi:10.1099/vir.0.82718-0

Marusic, C., Rizza, P., Lattanzi, L., Mancini, C., Spada, M., Belardelli, F., et al. (2001). Chimeric plant virus particles as immunogens for inducing murine and human immune responses against human immunodeficiency virus type 1 . J. Virol. 75, 8434-8439. doi:10.1128/JVI.75.18.8434-8439.2001

Melnik, S., and Stoger, E. (2013). Green factories for biopharmaceuticals. Curr. Med. Chem. 20, 1038-1046. doi:10.2174/0929867311320080007

Meunier, S., Strable, E., and Finn, M. G. (2004). Crosslinking of and coupling to viral capsid proteins by tyrosine oxidation. Chem. Biol. 11, 319-326. doi:10.1016/j. chembiol.2004.02.019

Morell, M., Espargaro, A., Aviles, F. X., and Ventura, S. (2007). Detection of transient protein-protein interactions by bimolecular fluorescence complementation: the Abl-SH3 case. Proteomics 7, 1023-1036. doi:10.1002/pmic.200600966

Morgenfeld, M., Segretin, M. E., Wirth, S., Lentz, E., Zelada, A., Mentaberry, A., et al. (2009). Potato virus X coat protein fusion to human papillomavirus 16 E7 oncoprotein enhance antigen stability and accumulation in tobacco chloroplast. Mol. Biotechnol. 43, 243-249. doi:10.1007/s12033-009-9195-3

Porta, C., and Lomonossoff, G. P. (1998). Scope for using plant viruses to present epitopes from animal pathogens. Rev. Med. Virol. 8, 25-41. doi:10.1002/ (SICI)1099-1654(199801/03)8:1<25::AID-RMV212>3.3.CO;2-M

Rego, J. M., Lee, J. H., Lee, D. H., and Yi, H. (2013). Biologically inspired strategy for programmed assembly of viral building blocks with controlled dimensions. Biotechnol. J. 8, 237-246. doi:10.1002/biot.201100504

Rosenthal, J. A., Chen, L., Baker, J. L., Putnam, D., and Delisa, M. P. (2014). Pathogen-like particles: biomimetic vaccine carriers engineered at the nanoscale. Curr. Opin. Biotechnol. 28, 51-58. doi:10.1016/j.copbio.2013.11.005

Sainsbury, F., Canizares, M. C., and Lomonossoff, G. P. (2010). Cowpea mosaic virus: the plant virus-based biotechnology workhorse. Annu. Rev. Phytopathol. 48, 437-455. doi:10.1146/annurev-phyto-073009-114242

Sette, A., Livingston, B., Mckinney, D., Appella, E., Fikes, J., Sidney, J., et al. (2001). The development of multi-epitope vaccines: epitope identification, vaccine design and clinical evaluation. Biologicals 29, 271-276. doi:10.1006/ biol.2001.0297

Shukla, S., Dickmeis, C., Nagarajan, A. S., Fischer, R., Commandeur, U., and Steinmetz, N. F. (2014). Molecular farming of fluorescent virus-based nanoparticles for optical imaging in plants, human cells and mouse models. Biomater. Sci. 2, 784-797. doi:10.1039/c3bm60277j
Simmonds, P., Bukh, J., Combet, C., Deleage, G., Enomoto, N., Feinstone, S., et al. (2005). Consensus proposals for a unified system of nomenclature of hepatitis C virus genotypes. Hepatology 42, 962-973. doi:10.1002/hep.20819

Steinmetz, N. F. (2010). Viral nanoparticles as platforms for next-generation therapeutics and imaging devices. Nanomedicine 6, 634-641. doi:10.1016/j. nano.2010.04.005

Sugiyama, Y., Hamamoto, H., Takemoto, S., Watanabe, Y., and Okada, Y. (1995). Systemic production of foreign peptides on the particle surface of tobacco mosaic virus. FEBS Lett. 359, 247-250. doi:10.1016/0014-5793(95)00054-D

Tollin, P., and Wilson, H. R. (1988). "Particle structure," in The Plant Viruses, ed. Milne R. G. (New York, NY: Plenum), 51-83.

Toth, R. L., Chapman, S., Carr, F., and Santa Cruz, S. (2001). A novel strategy for the expression of foreign genes from plant virus vectors. FEBS Lett. 489, 215-219. doi:10.1016/S0014-5793(01)02091-9

Twyman, R. M., Stoger, E., Schillberg, S., Christou, P., and Fischer, R. (2003). Molecular farming in plants: host systems and expression technology. Trends Biotechnol. 21, 570-578. doi:10.1016/j.tibtech.2003.10.002

Uhde, K., Fischer, R., and Commandeur, U. (2005). Expression of multiple foreign epitopes presented as synthetic antigens on the surface of Potato virus X particles. Arch. Virol. 150, 327-340. doi:10.1007/s00705-004-0402-Z

Uhde-Holzem, K., Fischer, R., and Commandeur, U. (2007). Genetic stability of recombinant potato virus $\mathrm{X}$ virus vectors presenting foreign epitopes. Arch. Virol. 152, 805-811. doi:10.1007/s00705-006-0892-y

Uhde-Holzem, K., Schlosser, V., Viazov, S., Fischer, R., and Commandeur, U. (2010). Immunogenic properties of chimeric potato virus $\mathrm{X}$ particles displaying the hepatitis C virus hypervariable region I peptide R9. J. Virol. Methods 166, 12-20. doi:10.1016/j.jviromet.2010.01.017

Verchot, J., Angell, S. M., and Baulcombe, D. C. (1998). In vivo translation of the triple gene block of potato virus $\mathrm{X}$ requires two subgenomic mRNAs. J. Virol. 72, 8316-8320.

Yusibov, V., Rabindran, S., Commandeur, U., Twyman, R. M., and Fischer, R. (2006). The potential of plant virus vectors for vaccine production. Drugs RD 7, 203-217. doi:10.2165/00126839-200607040-00001

Zilian, E., and Maiss, E. (2011). An optimized mRFP-based bimolecular fluorescence complementation system for the detection of protein-protein interactions in planta. J. Virol. Methods 174, 158-165. doi:10.1016/j. jviromet.2011.03.032

Conflict of Interest Statement: The authors declare that the research was conducted in the absence of any commercial or financial relationships that could be construed as a potential conflict of interest.

Copyright (c) 2015 Dickmeis, Honickel, Fischer and Commandeur. This is an open-access article distributed under the terms of the Creative Commons Attribution License (CC BY). The use, distribution or reproduction in other forums is permitted, provided the original author(s) or licensor are credited and that the original publication in this journal is cited, in accordance with accepted academic practice. No use, distribution or reproduction is permitted which does not comply with these terms. 